\title{
Analysis on the causes of the change in the north-south gap of industrial pollution discharge in China
}

\author{
Xiao-dong Zhang ${ }^{1} \mathbb{D} \cdot{\text { Bin } \mathrm{Li}^{1} \cdot \mathrm{Juan}^{\mathrm{Lu}} \mathrm{Lu}^{2} \cdot \mathrm{AL}-\text { Barakani Abdo }}^{1}$ \\ Received: 26 July 2021 / Accepted: 2 December 2021 / Published online: 10 January 2022 \\ (c) The Author(s), under exclusive licence to Springer-Verlag GmbH Germany, part of Springer Nature 2021
}

\begin{abstract}
What are the causes of the change in the north-south gap of industrial pollution discharge in 2008 and 2016 ? In order to solve this problem, this paper makes theoretical and empirical research. The results show that (1) the difference in economic growth pattern transformation is the root cause of the change in the north-south gap of industrial pollution discharge.(2) The international financial crisis is the direct cause of the change in the north-south gap of industrial pollution discharge in 2008. The international financial crisis forced the industrial transformation and upgrading of the southern region, which made the TFP of the southern region relatively improve, and then led to the relative reduction of industrial pollution discharge in the southern region. (3) The supply-side structural reform is the direct cause of the change in the north-south gap of industrial pollution discharge in 2016. However, the supply-side structural reform proposed by the central government in 2016 is essentially a further continuation of the policy of "resolving overcapacity" implemented in 2013. In fact, the north-south gap in the growth rate of industrial discharge has changed since 2013.
\end{abstract}

Keywords Industrial pollution discharge $\cdot$ North-south gap $\cdot$ International financial crisis $\cdot$ Supply-side structural reform

\section{Introduction}

At the 19th National Congress of the Communist Party of China (CPC) on October 18, 2017, President Xi Jinping pointed out that "as socialism with Chinese characteristics has entered a new era, the social principal contradiction has become that between unbalanced and inadequate development and the people's ever-growing needs for a better life." $\mathrm{Hu}$ et al. (2018) believe that unbalanced development mainly includes economic, social, cultural, and other aspects, while unbalanced regional development is an important part of unbalanced economic development. For a long time, the east-west gap has been the main manifestation of unbalanced regional development. But in recent years, the widening

Responsible Editor: Ilhan Ozturk

Xiao-dong Zhang

hnuzxd@sina.com

1 School of Economics and Trade, Hunan University, Yuelu District, Changsha City, Hunan Province, China

2 College of Economics and Management, Nanjing Agricultural University, Xuanwu District, Nanjing City, China north-south gap has gradually become a "new problem" of regional economic development, which has attracted wide attention from all walks of life (Sheng et al. 2018). Considering that economic growth is closely related to environmental pollution, is there also a north-south gap in industrial pollution discharge? With such a doubt, this paper analyzes the industrial pollution discharge ${ }^{1}$ in the north and south of China from 1998 to $2018^{2}$.

Figure 1 shows the proportion of industrial waste water discharge from north and south regions in the total industrial waste water discharge in China from 1998 to 2018. And Fig. 2 shows the proportion of industrial $\mathrm{SO}_{2}$ discharge from north and south regions in the total industrial $\mathrm{SO}_{2}$ discharge in China from 1998 to 2018. It can be seen from Fig. 1 and

\footnotetext{
${ }^{1}$ Industrial pollution mainly includes waste water pollution, waste gas pollution, and waste residue pollution. Because there are many missing data of industrial solid waste discharge, this paper mainly analyzes industrial wastewater discharge and industrial $\mathrm{SO}_{2}$ discharge.

${ }^{2}$ In this paper, the Qinling Mountains-Huaihe River line is taken as the dividing line between the north and the south. The northern areas include Beijing, Tianjin, Hebei, Shanxi, Inner Mongolia, Liaoning, Jilin, Heilongjiang, Shandong, Henan, Shaanxi, Gansu, Qinghai, Ningxia, and Xinjiang. The southern region includes Shanghai, Jiangsu, Zhejiang, Anhui, Fujian, Jiangxi, Hubei, Hunan, Guangdong, Guangxi, Hainan, Chongqing, Sichuan, Guizhou, and Yunnan. The research objects of this paper do not include Tibet.
} 


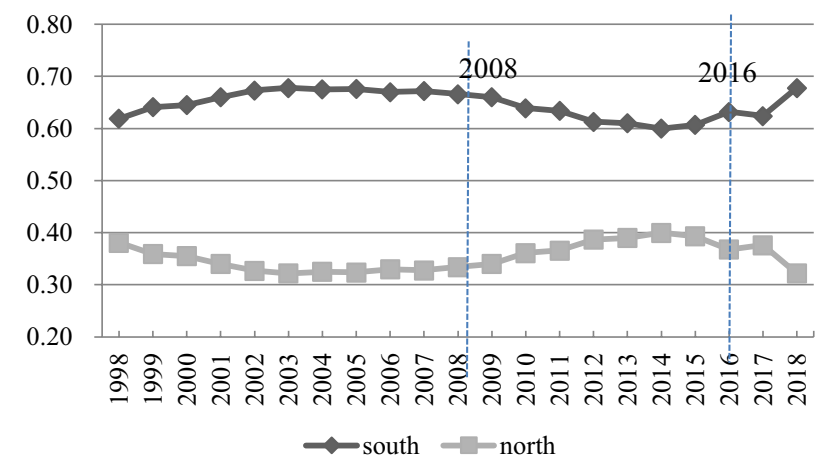

Fig. 1 The proportion of industrial wastewater discharge in north and south China

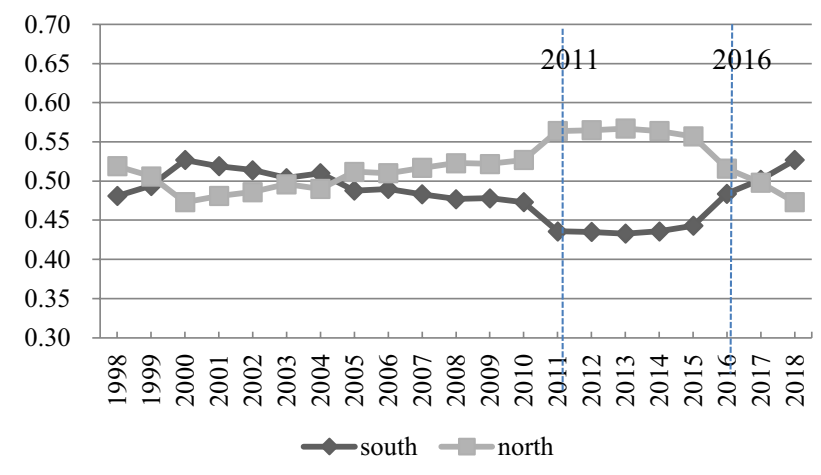

Fig. 2 The proportion of industrial $\mathrm{SO}_{2}$ discharge in north and south China

Fig. 2 that the industrial waste water discharge in the south is always greater than that in the north, while the industrial $\mathrm{SO}_{2}$ discharge in the south is always smaller than that in the north, and there is an objective north-south gap of industrial pollution discharge. At the same time, it can be seen that the north-south gap of industrial pollution discharge changed significantly around 2010 and 2016 . So, why did the northsouth gap in industrial pollution discharge change significantly around 2010 and 2016 ? Why is the change trend in the north-south gap of industrial wastewater discharge and the north-south gap of industrial $\mathrm{SO}_{2}$ discharge so different in the same time? How to make ecological development in the north and south more coordinated? The main purpose of this paper is to answer the above questions.

\section{Literature review}

Since the reform and opening up, the regional imbalance of environmental pollution is mainly manifested in the significant difference of environmental pollution levels in the eastern, central, and western regions. Therefore, studies on the regional gap of environmental pollution mostly focus on the east-west gap, while few scholars pay attention to the north-south gap. Generally speaking, scholars mainly study the east-west gap of environmental pollution from two aspects: one is the changing trend of the east-west gap in environmental pollution; the other is the formation reason of the east-west gap in environmental pollution. As for the changing trend of the east-west gap in environmental pollution, some scholars take a single pollutant as the research object. For example, Luo and Teng (2018), Shi et al. (2017), Liu et al. (2015), Yang and Liu (2012) respectively analyzed the regional differences and evolution characteristics of soil pollution, water pollution, air pollution, and carbon dioxide emissions. Other scholars take the overall level of regional pollution as the research object. Ding and Li (2010) calculated the regional pollution entropy by using three kinds of industrial waste discharge data, and used it to measure the regional pollution level. Liu et al. (2016) calculated the overall level of regional pollution through entropy method based on the discharge data of seven types of pollutants. Wang and $\mathrm{Xu}$ (2015) constructed a comprehensive environmental health index system including 22 three-level indicators, and evaluated the environmental health status of China from 2003 to 2010 by principal component analysis. In addition, Xinchen and Xingle (2016), Weiwei et al. (2020), Singpai and $\mathrm{Wu}$ (2020) all use environmental efficiency to measure regional environmental pollution level. Despite the differences in research objects and measurement methods, the consensus among scholars is that there are significant differences in environmental pollution levels in the eastern, central, and western regions, and that these differences are gradually narrowing.

As for the formation reasons of the east-west gap in environmental pollution, they can be roughly summarized into the following three aspects: Firstly, the regional income gap. According to the environmental Kuznets curve (EKC), the relationship between per capita income level and environmental pollution level presents an "inverted U-shaped" relationship. Since China is still on the left side of the EKC, the per capita income level is positively correlated with the environmental pollution level, so the gap in the per capita income level between the eastern and western regions leads to the gap in the environmental pollution level. The research results of Lin and Jiang (2009), Brajer et al. (2011), Qi and Wang (2015), Chen and Leizhu (2015) all proved the correctness of this conclusion. Second is the regional environmental regulation gap. Bao et al. (2013) studied from the perspective of environmental protection legislation, and believed that strengthening environmental protection law enforcement significantly inhibited pollution discharge. Yu and Gao (2015) studied from the perspective of hidden economy, and believed that China's current environmental regulation promoted 
pollution discharge instead. However, Zhang and Wei (2014), based on the above two viewpoints, believed that environmental regulation and pollution discharge presented an "inverted U-shaped" relationship. Although scholars' conclusions are not consistent, they all agree that environmental regulation has an important impact on pollution discharge, and the east-west gap in the intensity of environmental regulation does cause gap in environmental pollution level to a certain extent. Third is the regional industrial structure gap. Xiao and Liu (2014), Zhou and Fan (2016), Yuan et al. (2016) all showed that the proportion of the secondary industry was significantly positively correlated with pollution discharge, and the optimization and adjustment of industrial structure would reduce the proportion of the secondary industry and thus inhibit pollution discharge. In addition to the gap in industrial structures, some scholars have further studied the impact of industry structure gap on pollution discharge. The studies of Yuan and Xie (2012), Wang et al. (2014), and Cheng et al. (2014) all showed that industry structure is an important factor affecting regional pollution discharge. Pollution discharge can be significantly reduced by adjusting industry structure, especially by reducing the proportion of "high pollution, high energy consumption, high water consumption" industries. It can be seen that the east-west gaps in the industrial structure and industry structure also lead to the gap in environmental pollution level. In addition, the studies of Russo et al. (2019), Dong et al. (2020), Dutheil et al. (2020), and Huang et al. (2021) found that population density, tourism activities, COVID-19, and emission trading plan will also have an important impact on the regional gap of environmental pollution.

From the above analysis, it can be seen that there is abundant literature on the east-west gap in environmental pollution, and many scholars have analyzed the causes and changing trends of the east-west gap, which provides a useful reference for this paper. However, there is little literature on the north-south gap in environmental pollution, let alone empirical research on the reasons for the change of the gap. The contribution of this paper may be as follows: Firstly, it is the first time to study the north-south gap of industrial pollution discharge, which enriches literature on the regional gap of environmental pollution. Secondly, this paper analyses the causes of the change in north-south gap of industrial pollution discharge from the perspective of the transformation of economic growth pattern.

The contents of this paper are as follows: The first part is the introduction, which shows the objective situation of the north-south gap of industrial pollution discharge in China. The second part is literature review, which expounds relevant research results. The third part analyzes the reasons why the north-south gap of industrial pollution discharge changed around 2010 and 2016 , and puts forward hypotheses. The fourth part is the model construction and data description. The fifth part uses the DID model to empirically test the impact of the international financial crisis in 2008 and the supplyside structural reform in 2016 on the north-south gap in industrial pollution discharge. The sixth part is the result discussion, which comprehensively expounds the research results and comparison with relevant research. The seventh part, based on theoretical and empirical analysis, puts forward some suggestions to promote the coordinated development of the ecological environment in the north and south of China.

\section{Theoretical hypothesis}

Both the north-south gap of industrial wastewater discharge and the north-south gap industrial $\mathrm{SO}_{2}$ discharge changed greatly around 2010 and 2016. But why are the change trends of the two completely opposite? This chapter will solve this problem through a theoretical model. What caused the obvious change in the North-South gap of industrial pollution discharge around 2010 and 2016? This chapter will solve this problem through theoretical analysis.

\section{Theoretical model}

Suppose there is an industrial country A in the world. According to the division of geography and ecology, country $\mathrm{A}$ is divided into northern region $\mathrm{N}$ and southern region $\mathrm{S}$. Industrial production is carried out in both northern and southern regions, and the main pollutants in the process of industrial production are industrial wastewater and industrial $\mathrm{SO}_{2}$. Suppose that the discharge of industrial pollutant $i$ in the northern region in $t$ year is $N_{i, t}$, and the discharge of industrial pollutant $i$ in the southern region in $t$ year is $S_{i, t}$, $i=1,2$. 1 represents industrial wastewater and 2 represents industrial $\mathrm{SO}_{2}$. According to the definition of north-south gap, the north-south gap of the total discharge of industrial pollutant $i$ in year $t$ and year $t+1$ is $\left|\frac{S_{i, t}-N_{i, t}}{S_{i, t}+N_{i, t}}\right|$ and $\left|\frac{S_{i, t+1}-N_{i, t+1}}{S_{i, t+1}+N_{i, t+1}}\right|$, and the change of the north-south gap can be expressed as follows:

$g=\left|\frac{S_{i, t+1}-N_{i, t+1}}{S_{i, t+1}+N_{i, t+1}}\right|-\left|\frac{S_{i, t}-N_{i, t}}{S_{i, t}+N_{i, t}}\right|$

If $g>0$, the north-south gap will widen. If $g<0$, the northsouth gap will narrow. In order to further explore the influencing factors of the north-south gap change, suppose $S_{i, t+1}$ 
$=\left(1+a_{i, t+1}\right) S_{i, t}, N_{i, t+1}=\left(1+b_{i, t+1}\right) N_{i, t}$, and $a_{i, t+1}$ and $b_{i, t+1}$ respectively represent the growth rate of industrial pollutant $i$ in the south and north regions in $\mathrm{t}+1$ year. Then,
Although there is a significant difference in the change trend of industrial wastewater and industrial $\mathrm{SO}_{2}$ due to the different initial discharge, the reasons for the change

$g=\frac{\left|\left(1+a_{i, t+1}\right) S_{i, t}-\left(1+b_{i, t+1}\right) N_{i, t}\right|\left(S_{i, t}+N_{i, t}\right)-\left|S_{i, t}-N_{i, t}\right|\left[\left(1+a_{i, t+1}\right) S_{i, t}+\left(1+b_{i, t+1}\right) N_{i, t}\right]}{\left(S_{i, t+1}+N_{i, t+1}\right)\left(S_{i, t}+N_{i, t}\right)}$

For Equation (2), there are the following four cases.

Case 1: $S_{i, t}>N_{i, t}, S_{i, t+1}>N_{i, t+1}$. At this time, we can get

$g=\frac{2\left(a_{i, t+1}-b_{i, t+1}\right) S_{i, t} N_{i, t}}{\left(S_{i, t+1}+N_{i, t+1}\right)\left(S_{i, t}+N_{i, t}\right)}$

Case 2: $S_{i, t}>N_{i, t}, S_{i, t+1}<N_{i, t+1}$. At this time, we can get

$g=\frac{2\left(1+b_{i, t+1}\right) N_{i, t}^{2}-2\left(1+a_{i, t+1}\right) S_{i, t}^{2}}{\left(S_{i, t+1}+N_{i, t+1}\right)\left(S_{i, t}+N_{i, t}\right)}$

Case 3: $S_{i, t}<N_{i, t}, S_{i, t+1}>N_{i, t+1}$. At this time, we can get

$g=\frac{2\left(1+a_{i, t+1}\right) S_{i, t}^{2}-2\left(1+b_{i, t+1}\right) N_{i, t}^{2}}{\left(S_{i, t+1}+N_{i, t+1}\right)\left(S_{i, t}+N_{i, t}\right)}$

Case 4: $S_{i, t}<N_{i, t}, S_{i, t+1}<N_{i, t+1}$. At this time, we can get

$g=\frac{2\left(b_{i, t+1}-a_{i, t+1}\right) S_{i, t} N_{i, t}}{\left(S_{i, t+1}+N_{i, t+1}\right)\left(S_{i, t}+N_{i, t}\right)}$

Equations (3), (4), (5), and (6) respectively show the calculation results of the change of the north-south gap in different cases. According to the calculation results, the positive and negative values of G mainly depend on the $a_{i t+1}$ and $b_{i t+1}$, that is, the growth rate of industrial pollutant $i$ in the southern and northern regions in $t+1$ year.

Combining the calculation results of the theoretical model with the status of the north-south gap in industrial pollution discharge, it is found that the change of the north-south gap in industrial wastewater discharge is in line with case 1 , while the change of the north-south gap in industrial $\mathrm{SO}_{2}$ discharge is in line with case 4 . For industrial waste water, the total discharge in the south is always greater than that in the north. In 2008, the growth rate in the south was lower than that in the north. That is, $a_{i t+1}<b_{i t+1}$, so $g<0$, the north-south gap narrowed. In 2016, the growth rate in the south was higher than that in the north. That is, $a_{i t+1}>b_{i t+1}$, so $g>0$, the north-south gap widened. For industrial $\mathrm{SO}_{2}$, the total discharge in the south was lower than that in the north in 2011 and 2016. In 2011, the growth rate in the south was lower than that in the north. That is, $a_{i^{t} t+1}<b_{i^{\prime} t+1}$, so $g>0$, the north-south gap widened. In 2016, the growth rate in the south was higher than that in the north. That is, $a_{i t+1}>b_{i t+1}$, so $g<0$, the north-south gap narrowed. of the north-south gap between them are consistent. The reason why the north-south gap of industrial waste water discharge and industrial sulfur dioxide discharge changed around 2010 is that the growth rate of the southern region is less than that of the northern region (or the decline rate of the southern region is greater than that of the northern region). The reason why the north-south gap of industrial wastewater discharge and industrial sulfur dioxide discharge changed in 2016 is that the growth rate of the southern region is greater than that of the northern region (or the decline rate of the southern region is less than that of the northern region).

\section{Theoretical analysis}

Based on the theoretical model, this paper further explores the deep reasons for the change of the north-south gap. And this paper argues that the change of the northsouth gap in China's industrial pollution discharge is closely related to the transformation of economic growth pattern. In 2008, when the international financial crisis broke out, China's economic growth slowed down rapidly and its export trade was severely hit. In order to fight the international financial crisis, the central government of China introduced a series of economic stimulus measures, such as the "Four Trillion Investment Plan" and "Ten Major Industry Revitalization Plan." These measures were mainly implemented in infrastructure construction, steel, petrochemical, nonferrous metals, and other industries on which the northern region was highly dependent, supported inefficient and polluting enterprises that should have been withdrawn from the market, slowed down the pace of industrial transformation and upgrading in the northern region, and reduced the TFP and TFP contribution rate in the northern region (Deng et al. 2020). Compared with the northern region relying on capital-intensive industries to get out of the predicament, the southern region relied more on knowledgeintensive industries. The severe impact of the international financial crisis strengthened the determination of the local governments in the southern region to accelerate the pace of industrial transformation and upgrading. By eliminating backward industries and accelerating the development of knowledge-intensive industries, TFP and TFP contribution rate in southern China improved. Therefore, the growth rate of industrial pollution discharge in the south is less than that in the north around 2010. 
Although economic stimulus measures such as the "Four Trillion Investment Plan" temporarily stabilized economic growth in the northern region, and maintained the development of heavy chemical industries such as steel. However, with the recession of economic stimulus effect, these industries were immediately hit by weak domestic and foreign demand, overcapacity emerged, the investment-led growth pattern began to weaken, and structural contradictions gradually became prominent (Deng et al. 2020). In order to solve the structural problems, the central government began to vigorously promote the supply-side structural reform in 2016, and put forward the five priority tasks of cutting overcapacity, reducing excess inventory, deleveraging, lowering costs, and strengthening areas of weakness. Under the pressure of cutting overcapacity and reducing excess inventory, the northern region had to accelerate the transformation and upgrading of the heavy chemical industry, and eliminated backward production capacity that failed to meet environmental protection, energy consumption, quality, safety, and technical standards according to law. The industrial structure in the northern region was significantly optimized, and the TFP and TFP contribution rate were significantly improved. Compared with the northern region, on the one hand, the southern region was less dependent on the heavy chemical industry and undertook fewer "overcapacity reduction" tasks. On the other hand, the southern region has vigorously promoted the development of the Internet, artificial intelligence, and intelligent manufacturing since the international financial crisis. The industrial transformation and upgrading started earlier, and the TFP and TFP contribution rate are higher. Therefore, the supply-side structural reform had less impact on the southern region, and the decline rate of industrial pollution discharge in the north was greater than that in the south in 2016.

According to the theoretical analysis of the change in the north-south gap of industrial pollution discharge, this paper puts forward the following hypotheses:

Hypothesis 1: The international financial crisis is the direct cause of the narrowing north-south gap in industrial wastewater discharge in 2008 and the widening north-south gap in industrial $\mathrm{SO}_{2}$ discharge in 2011. The international financial crisis forced the industrial transformation and upgrading of the southern region, which made the TFP and TFP contribution rate relatively improve in southern China, and then led to the relative reduction of the growth rate in industrial pollution discharge and the relative reduction of industrial pollution discharge in southern China.

Hypothesis 2: The supply-side structural reform is the direct cause of the widening north-south gap in industrial wastewater discharge and the narrowing north-south gap in industrial $\mathrm{SO}_{2}$ discharge in 2016. The supply-side structural reform forced the industrial transformation and upgrading of the northern region, which made the TFP and
TFP contribution rate relatively improve in northern China, and then led to the relative reduction of the growth rate in industrial pollution discharge and the relative reduction of industrial pollution discharge in northern China.

\section{Material and method}

\section{Model building}

\section{Benchmark model}

In order to verify the correctness of the conclusions obtained from the status analysis and theoretical analysis, this paper constructs an econometric model based on logarithmic mean divisia index (LMDI). With reference to the decomposition ideas of Zhang and Wu (2015) and Liu et al. (2015), this paper decomposes industrial pollution discharge into Equation (7) :

$P=\frac{P}{F} \times \frac{F}{E} \times \frac{E}{V} \times \frac{V}{Y} \times Y=\mathrm{POF} \times \mathrm{FOE} \times \mathrm{EOV} \times \mathrm{VOY} \times Y$

In Equation (7), $P$ is industrial pollution discharge, $F$ is industrial pollution production, $E$ is industrial energy consumption, $V$ is industrial added value, and $Y$ is GDP. POV is the intensity of control measures of industrial pollution, which reflects the enthusiasm for pollution control. This paper thinks that POV is positively related to environmental regulation, and environmental regulation can improve POV. FOE refers to the amount of industrial pollutants produced by unit energy consumption. This paper believes that FOE has a significant negative correlation with technological innovation, and technological innovation can reduce FOE. At the same time, FOE is also closely related to foreign direct investment, but the influence of foreign direct investment on FOE has two sides. FOV is energy intensity, reflecting the energy efficiency in the process of industrial output. VOY represents the proportion of industrial added value to GDP, that is, industrial structure. It can be seen that industrial pollution discharge is closely related to environmental regulation, technological innovation, foreign direct investment, energy intensity, industrial structure, and GDP.

Based on the above analysis and by referring to the research ideas of Deng et al. (2020) on the north-south economic gap, this paper constructs the following benchmark model:

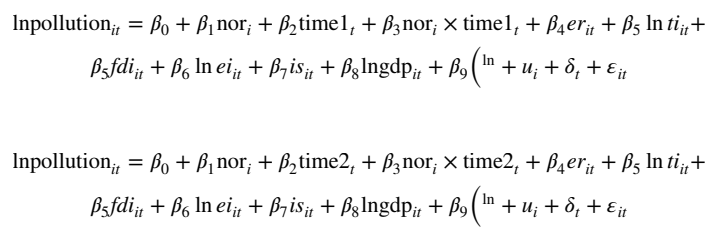


In the above Equation, $i$ and $t$ represent province and year respectively, and pollution is industrial pollution discharge. The nor is a regional dummy variable. If $i$ is a northern province, its value is 1 . If $i$ is a southern province, its value is 0 . Both time 1 and time 2 are time dummy variables. The time 1 is the start time of the international financial crisis, and the value is 0 before 2008 and 1 after 2008. The time 2 is the start time of the supplyside structural reform, and the value is 0 before 2016 and 1 after 2016. The control variables $e r, t i, f d i, e i, i s$, and $g d p$ respectively represent the environmental regulation intensity, technological innovation level, foreign capital utilization level, energy intensity, industrial structure, and economic development level of the province. $u_{i}$ is the province fixed effect, $\delta_{t}$ is the time fixed effect, and $\varepsilon_{i t}$ is the random disturbance term.

In addition, this paper also replaces the industrial pollution discharge with the growth rate of industrial pollution discharge, so as to further investigate the growth difference of industrial pollution discharge in the north and south regions. The specific model is as follows:

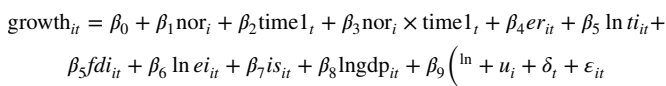

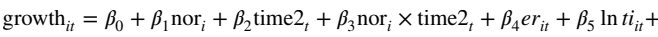

$\beta_{5} f d i_{i t}+\beta_{6} \ln e i_{i t}+\beta_{7} i s_{i t}+\beta_{8} \operatorname{lngdp}_{i t}+\beta_{9}\left(\ln +u_{i}+\delta_{t}+\varepsilon_{i t}\right.$

\section{Mediation model}

According to the previous theoretical analysis, this paper believes that the international financial crisis forced the industrial transformation and upgrading of the southern region, which made the TFP and TFP contribution rate relatively improve in southern China, and then led to the relative reduction of industrial pollution discharge in southern China. In order to verify the correctness of the influence mechanism, this paper uses the causal step method proposed by Baron and Kenny (1986) and Wen et al. (2004) to test the mediating effect, and establishes the following equations:

$$
\begin{aligned}
& \text { Inpollution }_{i t}=\alpha_{0}+\alpha_{1} \text { nor }_{i} \times \text { time }_{t}+\alpha_{2} e r_{i t}+\alpha_{3} \ln t i_{i t}+\alpha_{4} f d i_{i t}+\alpha_{5} \ln e i_{i t}+ \\
& \alpha_{6} i s_{i t}+\alpha_{7} \operatorname{lngdp}_{i t}+\alpha_{8}\left(\ln +u_{i}+\delta_{t}+\varepsilon_{i t}\right.
\end{aligned}
$$

Inpollution $_{i t}=\gamma_{0}+\gamma_{1}$ nor $_{i} \times$ time $_{t}+\gamma_{2} M_{i t}+\gamma_{3} e r_{i t}+\gamma_{4} \ln t i_{i t}+\gamma_{5} f d i_{i t}+$ $\gamma_{6} \ln e i_{i t}+\gamma_{7} i s_{i t}+\gamma_{8} \operatorname{lngdp_{it}}+\gamma_{9}\left(\ln +u_{i}+\delta_{t}+\varepsilon_{i t}\right.$

In the above equations, $M$ represents the intermediary variable, including total factor productivity $t f p$ and the economic endogenous growth rate $\mathrm{cr}$. According to the above equations, the following steps were followed for testing: Firstly, test the significance of $\alpha_{1}$. If $\alpha_{1}$ is significant, it indicates that the total effect of interaction term on industrial pollution discharge is significant. Then, test the significance of $\beta_{1}$ and $\gamma_{2}$ sequentially. If both $\beta_{1}$ and $\gamma_{2}$ are significant, the mediating effects of $t f p$ and $c r$ are significant. If one of them is not significant, the bootstrap test is necessary. Finally, test the significance of $\gamma_{1}$. If $\gamma_{1}$ is significant, it is a partial mediating effect, otherwise it is a complete mediating effect.

According to the previous theoretical analysis, this paper also believes that the supply-side structural reform forced the industrial transformation and upgrading of the northern region, which made the TFP and TFP contribution rate relatively improve in northern China, and then led to the relative reduction of the growth rate of industrial pollution discharge in northern China. In order to verify the correctness of the influence mechanism, this paper also uses the causal step method to test the mediating effect. The idea of model setting is the same as the previous, so it will not be repeated here.

$$
\begin{gathered}
\text { growth }_{i t}=\alpha_{0}+\alpha_{1} \text { nor }_{i} \times \operatorname{time}_{t}+\alpha_{2} e r_{i t}+\alpha_{3} \ln t_{i t}+\alpha_{4} f d i_{i t}+\alpha_{5} \ln e i_{i t}+ \\
\alpha_{6} i s_{i t}+\alpha_{7} \operatorname{lngdp}_{i t}+\alpha_{8}\left(\ln +u_{i}+\delta_{t}+\varepsilon_{i t}\right. \\
M_{i t}=\beta_{0}+\beta_{1} \text { nor }_{i} \times \operatorname{time~}_{t}+\beta_{2} e r_{i t}+\beta_{3} \ln t i_{i t}+\beta_{4} f d i_{i t}+\beta_{5} \ln e i_{i t}+ \\
\beta_{6} i s_{i t}+\beta_{7} \operatorname{lngdp}_{i t}+\beta_{8}\left(\ln +u_{i}+\delta_{t}+\varepsilon_{i t}\right.
\end{gathered}
$$

$$
\text { growth }_{i t}=\gamma_{0}+\gamma_{1} \text { nor }_{i} \times \text { time }_{t}+\gamma_{2} M_{i t}+\gamma_{3} e r_{i t}+\gamma_{4} \ln t i_{i t}+\gamma_{5} f d i_{i t}+
$$$$
\gamma_{6} \ln e i_{i t}+\gamma_{7} i i_{i t}+\gamma_{8} \operatorname{lngdp} i t+\gamma_{9}\left({ }^{\ln }+u_{i}+\delta_{t}+\varepsilon_{i t}\right.
$$

\section{Research method}

According to the constructed regression model, this paper will mainly use difference-in-difference (DID) to test the impact of the international financial crisis in 2008 and the supply-side structural reform in 2016 on the north-south gap of industrial pollution discharge. The research ideas of this paper are as follows: Firstly, DID regression is carried out according to the benchmark model. Secondly, the robustness test is carried out by common trend test, making up experimental groups and policy time, and changing sample time range to ensure the robustness of regression results. Then, the mediation model is used to test the influencing mechanism. Finally, the heterogeneity analysis is carried out from two aspects: industry structure and economic extroversion.

\section{Variable description}

In order to explore the causes of the change in the northsouth gap of industrial pollution discharge, this paper selects 
the provincial panel data of 30 Chinese provinces (excluding Tibet) from 1998 to 2018 as the research object. When analyzing the causes of the change in the north-south gap of industrial pollution discharge in 2008, the sample period is from 1998 to 2013. When analyzing the causes of the change in the north-south gap of industrial pollution discharge in 2016, the sample period is from 2005 to 2018.

\section{Explained variables}

pollution $_{i t}$ : It represents the industrial pollution discharge of province $i$ in $t$ year, which mainly includes industrial wastewater discharge and industrial $\mathrm{SO}_{2}$ discharge. In the empirical process, the per capita industrial wastewater discharge $i w w$ and per capita $\mathrm{SO}_{2}$ discharge $i w g$ are selected for regression analysis, and the original data of both are from China Environmental Statistics Yearbook and the statistical yearbook of each province.

growth $_{i t}$ It represents the growth rate of industrial pollution discharge of province $i$ in $t$ year, which also includes growth rate of industrial wastewater discharge giww and growth rate of industrial $\mathrm{SO}_{2}$ discharge giwg. The original data of the total amount of industrial pollution discharge come from China Environmental Statistical Yearbook and the statistical yearbooks of each province, and the growth rate of the total amount of industrial pollution discharge is obtained by calculation.

\section{Core explanatory variables}

In Equation (8), the interaction nor $\times$ time 1 measures how the international financial crisis affects the change of industrial pollution discharge in the northern region relative to the southern region. If the regression coefficient is positive, it indicates that the international financial crisis has caused the relative increase of industrial pollution discharge in northern China. If the regression coefficient is negative, it indicates that the international financial crisis has caused the relative decrease of industrial pollution discharge in northern China. Similarly, in Equation (10), the interaction term nor $\times$ time 1 measures the impact of the international financial crisis on the growth rate of industrial pollution discharge in the north and south regions.

In Equation (9), the interaction nor $\times$ time 2 measures how the supply-side structural reform affects the change of industrial pollution discharge in the northern region relative to the southern region. If the regression coefficient is positive, it indicates that the supply-side structural reform has caused the relative increase of industrial pollution discharge in northern China. If the regression coefficient is negative, it indicates that the supply-side structural reform has caused the relative decrease of industrial pollution discharge in northern China. Similarly, in Equation (11), the interaction term nor $\times$ time 2 measures the impact of the supply-side structural reform on the growth rate of industrial pollution discharge in the north and south regions.

\section{Control variables}

$e r_{i t}$ : It represents the environmental regulation intensity of province $i$ in $t$ year. This paper refers to the method used by Zhang et al. (2011), and uses the proportion of the industrial pollution abatement investment in the industrial added value to measure. Generally speaking, the higher the environmental regulation intensity in a region, the greater the industrial pollution abatement investment, and the less the industrial pollution discharge (He et al. 2015). Therefore, it is expected that environmental regulation intensity is negatively correlated with industrial pollution discharge, and the original data is from China Statistical Yearbook.

$t i_{i t}$ : It represents the technology innovation level of province $i$ in $t$ year, which is measured by the per capita patent application authorization (Shi et al. 2018), and the unit is piece per 10,000 people. At present, scholars generally agree with the discharge reduction effect of technological innovation. Technological innovation can reduce industrial pollution discharge by improving energy consumption structure and energy utilization efficiency (Wang and Xie 2014). The original data of the patent application authorization comes from the State Intellectual Property Office and CSMAR database.

$f d i_{i t}$ : It represents the foreign capital utilization level of province $i$ in $t$ year, which is measured by FDI over GDP. There are two different views on the impact of FDI on environmental pollution in the academic circles. The "Pollution Halo Hypothesis" holds that FDI can reduce the environmental pollution of the host country through technology spillover effect. However, the "Pollution Haven Hypothesis" holds that FDI will make pollution-intensive enterprises transfer from developed countries to developing countries, and increase the environmental pollution of the host country (Liu and Zhao 2016, Li et al. 2017). The original data of FDI comes from the China Statistical Yearbook and is converted according to the annual average exchange rate provided by the National Bureau of Statistics.

$e i_{i t}$ : It represents the energy intensity of province $i$ in $t$ year, which is measured by the ratio of industrial energy consumption to industrial added value, and the unit is ton of standard coal per 10,000 Yuan. Energy intensity reflects the comprehensive utilization efficiency of regional energy. The higher the energy intensity, the more energy consumed per unit output value, and the more industrial pollution discharge. Therefore, this paper expects that energy intensity is positively correlated with industrial pollution discharge. Since only a very few provinces have published industrial energy consumption data, this paper uses total energy 
consumption data as a substitute in the empirical process, and the original data is from China Energy Statistical Yearbook. The original data of industrial added value comes from China Statistical Yearbook, and we take 1998 as the base year, calculate the real industrial added value according to the GDP deflator.

$i s_{i t}$ : It represents the industrial structure of province $i$ in $t$ year, which is measured by industrial added value over GDP. Generally speaking, the proportion of industrial added value is positively correlated with the industrial pollution discharge. The higher the proportion of industrial added value, the more industrial pollution discharge (Friedl and Getzner 2003). The original data of industrial added value and GDP come from China Statistical Yearbook.

$g d p_{i t}$ : It represents the economic development level of province $i$ in $t$ year, which is measured by real per capita GDP, and the unit is Yuan per person. According to the EKC, there is an "inverted U-shaped" relationship between economic development level and industrial pollution discharge, so this paper adds the square term of economic development level into the model. The original data of per capita GDP comes from China Statistical Yearbook, and we take 1998 as the base year, calculate the real per capita GDP according to the GDP deflator.

\section{Intermediary variable}

$t f p_{i t}$ : It represents the total factor productivity of province $i$ in $t$ year. Total factor productivity is calculated by DEASBM model, and its original data includes labor input, capital input, and economic output. Labor input is measured by the number of employees at the end of the year, the unit is 10,000 people. Capital input is measured by the capital stock at constant price; the unit is 100 million Yuan. Economic output is measured by the real GDP whose base year is 1998; the unit is 100 million Yuan. The data of the three are all from the China Statistical Yearbook.

$c r_{i t}$ : It represents the economic endogenous growth rate of province $i$ in $t$ year. The economic endogenous growth rate is the contribution rate of total factor productivity to economic growth. It is calculated by $t f p$ and $g d p$ (Table 1).

\section{Results}

\section{Empirical analysis on the causes of the change in north-south gap in 2008}

\section{Benchmark regression results}

The regression results of the benchmark model are shown in Table 2. In Table 2, columns (1) and (2) are the regression
Table 1 Descriptive statistics of variables

\begin{tabular}{llllll}
\hline Variable & Unit & Mean & Std & Minimum & Maximum \\
\hline$i w w$ & tons/person & 15.43 & 8.77 & 3.25 & 61.49 \\
iwg & $\mathrm{kg} /$ person & 14.25 & 10.41 & 0.07 & 60.70 \\
giww & $/$ & -0.01 & 0.17 & -0.58 & 1.67 \\
giwg & $/$ & -0.04 & 0.21 & -0.81 & 1.29 \\
er & $/$ & 0.0044 & 0.0037 & 0.0004 & 0.0286 \\
$t i$ & piece/10,000 & 4.77 & 8.30 & 0.11 & 57.33 \\
& $\quad$ people & & & & \\
fdi & $/$ & 0.0266 & 0.0245 & 0.0001 & 0.1560 \\
ei & tons/10,000 Yuan & 4.66 & 3.14 & 1.11 & 16.71 \\
$i s$ & $/$ & 0.38 & 0.08 & 0.12 & 0.60 \\
gdp & Yuan/person & 22606 & 18,429 & 2364 & 119,203 \\
$t f p$ & $/$ & 1.0046 & 0.0373 & 0.744 & 1.095 \\
$c r$ & $/$ & 0.0208 & 0.4112 & -3.40 & 2.361 \\
\hline
\end{tabular}

results without adding other control variables. Columns (3) and (4) are the regression results with control variables but without individual and time fixed effects. Columns (5) and (6) are the regression results with control variables, individual and time fixed effects. Columns (7) and (8) are the regression results of the growth rate of industrial pollution discharge.

From the perspective of the core explanatory variables, before adding control variables, the influence of the international financial crisis on the north-south gap of industrial wastewater discharge and industrial $\mathrm{SO}_{2}$ discharge is not obvious. After adding control variables, the influence of the international financial crisis on the north-south gap of industrial $\mathrm{SO}_{2}$ discharge becomes significant, but the influence on the north-south gap of industrial wastewater discharge is still not obvious. Furthermore, adding individual and time fixed effects, the influences of the international financial crisis on the two are significantly positive, indicating that the international financial crisis makes the industrial wastewater discharge and industrial $\mathrm{SO}_{2}$ discharge in the northern region increase significantly compared with the southern region, or the international financial crisis makes the industrial wastewater discharge and industrial $\mathrm{SO}_{2}$ discharge in the southern region decrease significantly compared with the northern region. The benchmark regression results are consistent with the visual conclusions in Fig. 1 and Fig. 2, which preliminarily proves the correctness of Hypothesis 1 . The coefficient of the interaction term is no longer significant after the industrial pollution discharge is replaced by the growth rate of industrial pollution discharge, indicating that the international financial crisis has no obvious impact on the growth rate of industrial pollution discharge compared with the industrial pollution discharge.

From the perspective of control variables, the regression coefficients of environmental regulation intensity are both 
Table 2 The impact of the international financial crisis on the north-south gap in industrial pollution discharge

\begin{tabular}{|c|c|c|c|c|c|c|c|c|}
\hline Variable & $\begin{array}{l}(1) \\
i w w\end{array}$ & $\begin{array}{l}\text { (2) } \\
i w g\end{array}$ & $\begin{array}{l}(3) \\
i w w\end{array}$ & $\begin{array}{l}\text { (4) } \\
\text { iwg }\end{array}$ & $\begin{array}{l}(5) \\
i w w\end{array}$ & $\begin{array}{l}\text { (6) } \\
i w g\end{array}$ & $\begin{array}{l}\text { (7) } \\
\text { giww }\end{array}$ & $\begin{array}{l}\text { (8) } \\
\text { giwg }\end{array}$ \\
\hline nor & $\begin{array}{l}-0.259^{* * * *} \\
(-4.41)\end{array}$ & $\begin{array}{l}0.365^{\text {*** }} \\
(5.49)\end{array}$ & $\begin{array}{l}-0.395^{* * *} \\
(-6.55)\end{array}$ & $\begin{array}{l}-0.244^{* * * *} \\
(-3.95)\end{array}$ & & & & \\
\hline time1 & $\begin{array}{l}-0.068 \\
(-0.86)\end{array}$ & $\begin{array}{l}-0.026 \\
(-0.41)\end{array}$ & $\begin{array}{l}-0.409^{* * *} \\
(-5.34)\end{array}$ & $\begin{array}{l}-0.296^{* *} \\
(-4.63)\end{array}$ & $\begin{array}{l}-1.101^{* * * *} \\
(-2.74)\end{array}$ & $\begin{array}{l}-0.692 \\
(-0.90)\end{array}$ & $\begin{array}{l}0.339^{*} \\
(1.80)\end{array}$ & $\begin{array}{l}0.479^{* *} \\
(2.32)\end{array}$ \\
\hline nor $\times$ time 1 & $\begin{array}{l}0.103 \\
(1.06)\end{array}$ & $\begin{array}{l}0.178^{*} \\
(1.65)\end{array}$ & $\begin{array}{l}0.103 \\
(1.28)\end{array}$ & $\begin{array}{l}0.209^{* * *} \\
(2.85)\end{array}$ & $\begin{array}{l}0.175^{* *} \\
(2.06)\end{array}$ & $\begin{array}{l}0.169^{*} \\
(1.77)\end{array}$ & $\begin{array}{l}0.024 \\
(0.63)\end{array}$ & $\begin{array}{l}0.010 \\
(0.32)\end{array}$ \\
\hline$e r$ & & & $\begin{array}{l}14.578^{* * *} \\
(2.36)\end{array}$ & $\begin{array}{l}38.139^{* * * *} \\
(5.96)\end{array}$ & $\begin{array}{l}4.161 \\
(0.55)\end{array}$ & $\begin{array}{l}7.471 \\
(1.40)\end{array}$ & $\begin{array}{l}-3.486 \\
(-1.04)\end{array}$ & $\begin{array}{l}-2.162 \\
(-0.75)\end{array}$ \\
\hline $\ln t i$ & & & $\begin{array}{l}0.031 \\
(0.62)\end{array}$ & $\begin{array}{l}0.050 \\
(1.10)\end{array}$ & $\begin{array}{l}0.082 \\
(1.37)\end{array}$ & $\begin{array}{l}-0.131^{* *} \\
(-2.23)\end{array}$ & $\begin{array}{l}-0.081^{*} \\
(-1.85)\end{array}$ & $\begin{array}{l}-0.054 \\
(-1.57)\end{array}$ \\
\hline$f d i$ & & & $\begin{array}{l}1.284^{*} \\
(1.82)\end{array}$ & $\begin{array}{l}-2.549^{* * *} \\
(-3.00)\end{array}$ & $\begin{array}{l}-3.036^{*} \\
(-1.93)\end{array}$ & $\begin{array}{l}0.463 \\
(0.37)\end{array}$ & $\begin{array}{l}0.376 \\
(0.58)\end{array}$ & $\begin{array}{l}1.238 \\
(1.68)\end{array}$ \\
\hline lnei & & & $\begin{array}{l}0.038 \\
(0.50)\end{array}$ & $\begin{array}{l}0.764^{* * * *} \\
(12.93)\end{array}$ & $\begin{array}{l}0.928^{* * * *} \\
(4.02)\end{array}$ & $\begin{array}{l}0.551^{\text {** }} \\
(2.08)\end{array}$ & $\begin{array}{l}0.056 \\
(0.33)\end{array}$ & $\begin{array}{l}-0.045 \\
(-0.29)\end{array}$ \\
\hline is & & & $\begin{array}{l}2.640^{* * * *} \\
(9.00)\end{array}$ & $\begin{array}{l}4.862^{* * * *} \\
(14.51)\end{array}$ & $\begin{array}{l}0.949^{*} \\
(1.83)\end{array}$ & $\begin{array}{l}0.484 \\
(0.54)\end{array}$ & $\begin{array}{l}-0.433^{*} \\
(-1.88)\end{array}$ & $\begin{array}{l}-0.357 \\
(-1.42)\end{array}$ \\
\hline $\operatorname{lng} d p$ & & - & $\begin{array}{l}2.158^{* * * *} \\
(3.73)\end{array}$ & $\begin{array}{l}-0.106 \\
(-0.20)\end{array}$ & $\begin{array}{l}2.674^{* * * *} \\
(2.76)\end{array}$ & $\begin{array}{l}4.374^{* * *} \\
(4.26)\end{array}$ & $\begin{array}{l}0.321 \\
(0.48)\end{array}$ & $\begin{array}{l}-0.257 \\
(-0.58)\end{array}$ \\
\hline$(\ln g d p)^{2}$ & & & $\begin{array}{l}-0.098^{* * *} \\
(-3.29)\end{array}$ & $\begin{array}{l}0.019 \\
(0.74)\end{array}$ & $\begin{array}{l}-0.104^{* *} \\
(-2.19)\end{array}$ & $\begin{array}{l}-0.185^{\text {**** }} \\
(-4.53)\end{array}$ & $\begin{array}{l}-0.023 \\
(-0.69)\end{array}$ & $\begin{array}{l}-0.001 \\
(-0.02)\end{array}$ \\
\hline$u_{i}$ & no & no & no & no & yes & yes & yes & yes \\
\hline$\delta_{t}$ & no & no & no & no & yes & yes & yes & yes \\
\hline$R^{2}$ & 0.047 & 0.131 & 0.445 & 0.571 & 0.374 & 0.535 & 0.107 & 0.308 \\
\hline Obs & 480 & 480 & 480 & 480 & 480 & 480 & 480 & 480 \\
\hline
\end{tabular}

$*, * *, * * *$ respectively represent that the estimated values of parameters are significant at the levels of $10 \%, 5 \%$, and $1 \%$. The value of $T$ is in parentheses positive in columns (5) and (6), but both do not pass the significance test at the $10 \%$ level, and the coefficient signs do not match the expectation. The reason for this result is that the measurement methods of environmental regulation are diverse. The measurement methods used in this paper may not be able to accurately measure the intensity of environmental regulation, so the regression results are not significant. The regression coefficient of technological innovation level in column (6) is -0.131 , which passes the significance test at the 5\% level, indicating that technological innovation reduces industrial $\mathrm{SO}_{2}$ discharge. According to the previous analysis, technological innovation has discharge reduction effect and can reduce industrial $\mathrm{SO}_{2}$ discharge by improving energy consumption structure and energy utilization efficiency. The regression coefficient of foreign capital utilization level in column (5) is -3.036 , which passes the significance test at the $10 \%$ level. It shows that FDI reduces industrial wastewater discharge to some extent, and supports the "Pollution Halo Hypothesis." The regression coefficients of energy intensity are significantly positive in columns (5) and (6), indicating that energy intensity has a significant positive correlation with industrial pollution discharge. According to the previous analysis, the higher the energy intensity, the lower the regional comprehensive energy utilization efficiency, the more energy consumed per unit output value, and the more industrial pollution discharge. The regression coefficients of industrial structure are positive in both column (5) and column (6), and the coefficient signs are consistent with the expectation, indicating that the proportion of industrial added value is positively correlated with industrial pollution discharge. However, the regression coefficient of industrial structure does not pass the significance test at the $10 \%$ level in column (6), which may be related to the sample interval and model setting. In columns (5) and (6), the quadratic coefficients of economic development level are significantly negative, and the primary coefficients are significantly positive. It indicates an "inverted U-shaped" relationship between economic development level and industrial pollution discharge, which is consistent with EKC.

\section{Robustness test}

In order to ensure the robustness of benchmark regression results, this paper uses four methods to test robustness. Firstly, common trend test. Figures 3 and 4 show the results of common trend tests (95\% confidence intervals) for industrial wastewater discharge and industrial $\mathrm{SO}_{2}$ discharge respectively. As can be seen from Fig. 3, before the 


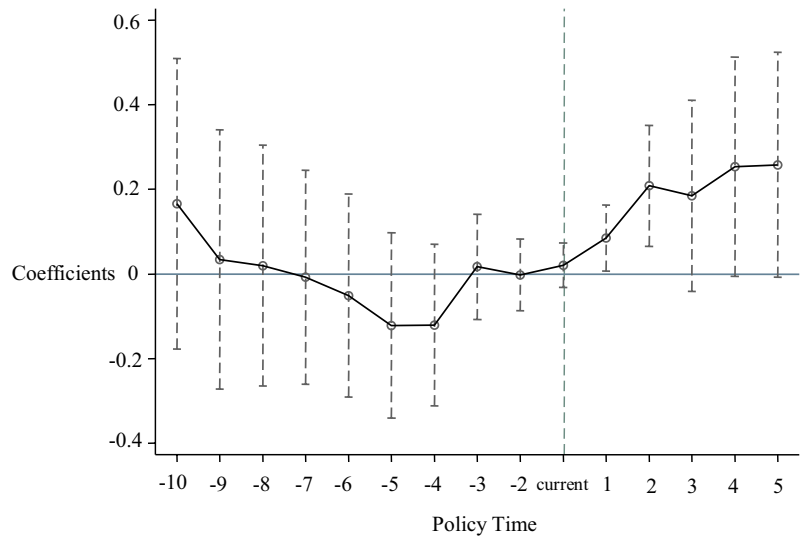

Fig. 3 Common trend test results of industrial wastewater discharge

international financial crisis, the interaction coefficients of different years were not significant, indicating that there was no significant difference in industrial wastewater discharge between the north and the south before the international financial crisis. After the international financial crisis, the interaction coefficients are significantly positive, indicating that there is a significant difference in industrial wastewater discharge between the north and the south under the influence of the international financial crisis. Similarly, for industrial $\mathrm{SO}_{2}$ discharge, the interaction coefficients didn't pass the significance test at the $10 \%$ level before the international financial crisis, but were significantly positive after the international financial crisis, indicating that the international financial crisis affected the industrial $\mathrm{SO}_{2}$ discharge in the northern and southern regions. Both industrial wastewater discharge and industrial $\mathrm{SO}_{2}$ discharge pass the common trend test, which preliminarily proves the robustness of DID regression results.

Secondly is the make up experimental groups. The specific method is as follows: We randomly select 15 provinces from the sample as "pseudo northern provinces," conduct DID regression according to the benchmark model. We repeat the experiment 1000 times and record the regression coefficient and significance level of the interaction items. If the benchmark regression result is obviously different from repeated sampling result, it is proved that the benchmark regression result is robust. If there is little difference between the benchmark regression result and the repeated sampling result, it is proved that the benchmark regression result is not robust. Figure 5 shows the distribution of interaction coefficients after repeating the experiment 1000 times. As can be seen from the left figure, for industrial wastewater discharge, most of the estimated values are concentrated around the 0 , which is far less than the benchmark estimated value of 0.175 in column (5) of Table 2. At the same time, the $P$ values of most coefficients are greater than 0.1 , which

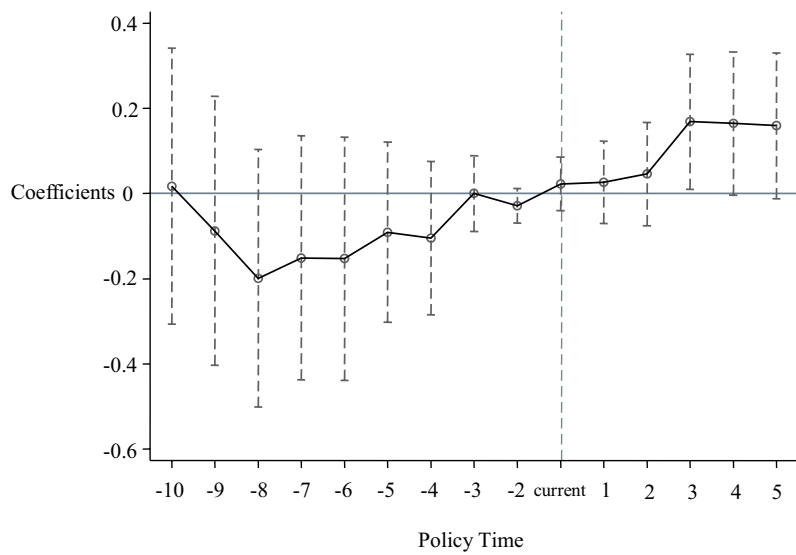

Fig. 4 Common trend test results of industrial $\mathrm{SO}_{2}$ discharge

do not pass the significance test at the $10 \%$ level. It can be seen that there are significant differences between the benchmark regression results and the repeated sampling results, and DID regression results based on the real grouping in this paper are highly reliable. Similarly, as can be seen from the right figure, for industrial $\mathrm{SO}_{2}$ discharge, the benchmark regression result of 0.169 is much larger than most of the estimated values, and its $P$ value is much smaller than the $P$ value of most coefficients, so the regression result is robust.

Thirdly is the make up policy time. Specifically, this paper advances the time of the international financial crisis, and conducts DID regression according to the benchmark model. If the interaction coefficient is not significant, it proves that the international financial crisis causes the change in the north-south gap of industrial pollution discharge. If the interaction coefficient is significant, it proves that our research conclusion is not robust. Table 3 shows the results of the placebo test with 2000-2007 as the policy time. It can be seen from Table 3 that the interaction coefficients are no longer significant after the time of the international financial crisis is advanced by $1-8$ years, indicating that the change in the north-south gap of industrial pollution discharge is indeed caused by the international financial crisis. At the same time, as the "pseudo policy time" approaches to real policy time, the interaction coefficient also turns from negative to positive and gradually approaches the benchmark estimate. The placebo test results are consistent with the common trend test results, and further prove the robustness of the benchmark regression results.

Fourthly is the changing of the time range of the sample. Based on the research method of Shi et al. (2018), this paper studies the sensitivity of the international financial crisis to time change by changing the time range of the sample. Specifically, the year when the international financial crisis occurred, is taken as the intermediate point, and the data of $1,2,3$, and 4 years before and after are selected for DID 

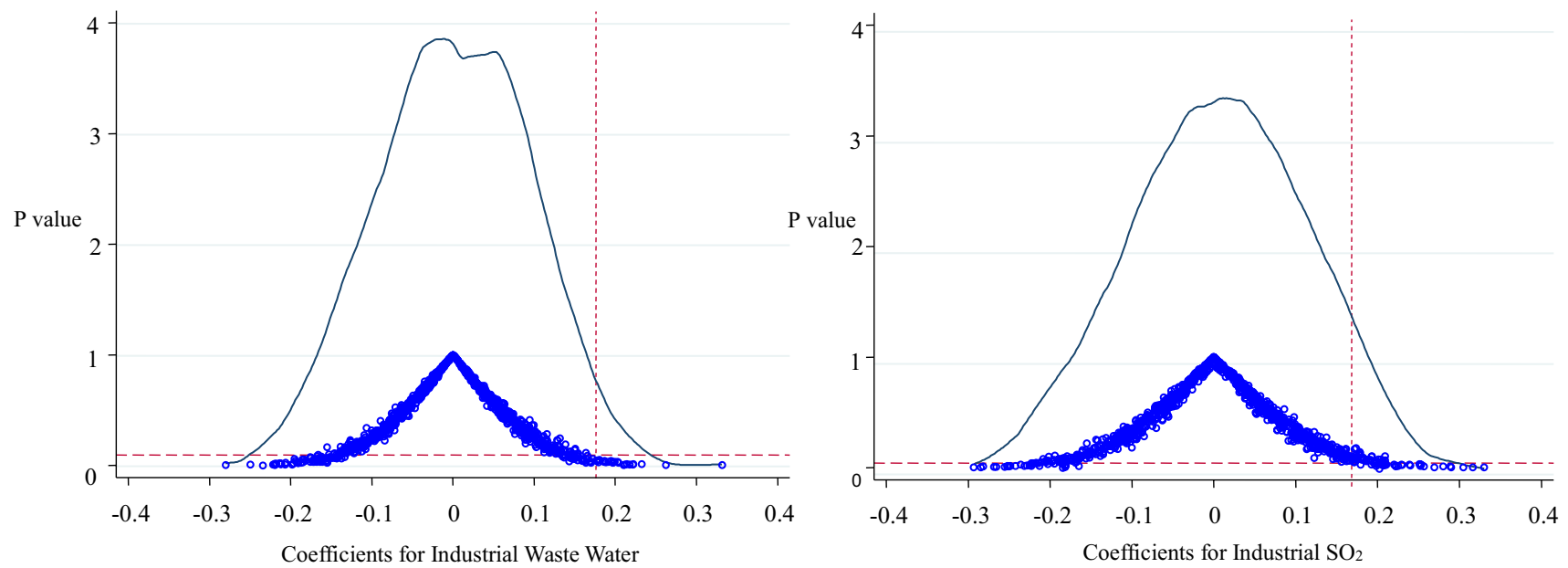

Fig. 5 Placebo test results based on fictitious experimental groups

Table 3 Placebo test results based on fictitious policy time

\begin{tabular}{lllllllll}
\hline Variable & $(9)$ & $(10)$ & $(11)$ & $(12)$ & $(13)$ & $(14)$ & $(15)$ & $(16)$ \\
& 2000 & 2001 & 2002 & 2003 & 2004 & 2005 & 2006 & 2007 \\
\hline nor $\times$ time 1 & -0.076 & -0.046 & -0.019 & 0.017 & 0.071 & 0.123 & 0.131 & 0.149 \\
$($ iww $)$ & $(-0.74)$ & $(-0.47)$ & $(-0.20)$ & $(0.17)$ & $(0.74)$ & $(1.24)$ & $(1.39)$ & $(1.67)$ \\
nor $\times$ time 1 & -0.007 & 0.068 & 0.101 & 0.133 & 0.146 & 0.166 & 0.158 & 0.164 \\
$($ iwg $)$ & $(-0.071)$ & $(0.62)$ & $(0.88)$ & $(1.05)$ & $(1.18)$ & $(1.36)$ & $(1.43)$ & $(1.61)$ \\
Control & yes & yes & yes & yes & yes & yes & yes & yes \\
$u_{i}$ & yes & yes & yes & yes & yes & yes & yes & yes \\
$\delta_{t}$ & yes & yes & yes & yes & yes & yes & yes & yes \\
$R^{2}(i w w)$ & 0.349 & 0.348 & 0.347 & 0.347 & 0.351 & 0.360 & 0.362 & 0.367 \\
$R^{2}(i w g)$ & 0.518 & 0.519 & 0.523 & 0.527 & 0.530 & 0.535 & 0.534 & 0.535 \\
Obs & 480 & 480 & 480 & 480 & 480 & 480 & 480 & 480 \\
\hline
\end{tabular}

regression. If the regression results of the interaction term have no significant change compared with the benchmark estimate, the benchmark regression result is robust. Table 4 shows the robustness test results for changing the time range. As can be seen from Table 4, after changing the time range of the samples, except for the samples of 1 year before and after, the interaction coefficients of all the other samples are significantly positive. The test results are consistent with the results of the benchmark regression, which proves the robustness of the research conclusions in this paper again. The interaction coefficient is not significant in the samples of 1 year before and after, possibly because the sample number is too small, which does not affect the results of robustness test.

\section{Influence mechanism test}

Table 5 and Table 6 show the test results of $t f p$ and $c r$ respectively. For $t f p$, it can be seen from Table 5 that the interaction coefficient in column (25) is significantly positive, indicating that the international financial crisis relatively reduces the industrial wastewater discharge in the south. The interaction coefficient in column (26) is significantly negative, indicating that the international financial crisis relatively improves the total factor productivity in the south. Although the regression coefficient of $t f p$ in column (27) is not significant, it passes the bootstrap test, indicating that the international financial crisis can relatively reduce the industrial wastewater discharge in the south by improving the total factor productivity in the south, thus narrowing the north-south gap of industrial wastewater discharge. At the same time, the interaction coefficient in column (27) is significant, indicating that the mediation effect of $t f p$ belongs to partial mediating effect. Similarly, for $\mathrm{cr}$, according to Table 6 , the interaction coefficient in column (31) is significantly positive, indicating that the international financial crisis relatively reduces the industrial wastewater discharge in the south. The interaction coefficient in column (32) is significantly negative, indicating that the international financial crisis relatively 
Table 4 Robustness test results based on changing sample time range

\begin{tabular}{|c|c|c|c|c|c|c|c|c|}
\hline \multirow[t]{3}{*}{ Variable } & \multicolumn{4}{|c|}{ Industrial wastewater } & \multicolumn{4}{|c|}{ Industrial $\mathrm{SO}_{2}$} \\
\hline & (17) & (18) & (19) & (20) & (21) & (22) & (23) & (24) \\
\hline & 1 year & 2 years & 3 years & 4 years & 1 year & 2 years & 3 years & 4 years \\
\hline nor $\times$ timel & $\begin{array}{l}0.041 \\
(1.51)\end{array}$ & $\begin{array}{l}0.079^{* * *} \\
(2.25)\end{array}$ & $\begin{array}{l}0.099^{* * *} \\
(2.24)\end{array}$ & $\begin{array}{l}0.171^{* * *} \\
(3.39)\end{array}$ & $\begin{array}{l}0.052 \\
(1.65)\end{array}$ & $\begin{array}{l}0.088^{* *} \\
(2.38)\end{array}$ & $\begin{array}{l}0.103^{* *} \\
(2.63)\end{array}$ & $\begin{array}{l}0.141^{* * * *} \\
(2.83)\end{array}$ \\
\hline Control & yes & yes & yes & yes & yes & yes & yes & yes \\
\hline$u_{i}$ & yes & yes & yes & yes & yes & yes & yes & yes \\
\hline$\delta_{t}$ & yes & yes & yes & yes & yes & yes & yes & yes \\
\hline$R^{2}$ & 0.436 & 0.343 & 0.341 & 0.296 & 0.762 & 0.726 & 0.614 & 0.518 \\
\hline Obs & 90 & 150 & 210 & 270 & 90 & 150 & 210 & 270 \\
\hline
\end{tabular}

$*, * *, * * *$ respectively represent that the estimated values of parameters are significant at the levels of $10 \%, 5 \%$, and $1 \%$. The value of $T$ is in parentheses

\begin{tabular}{|c|c|c|c|c|c|c|}
\hline \multirow[t]{3}{*}{ Variable } & \multicolumn{3}{|c|}{ Industrial wastewater } & \multicolumn{3}{|c|}{ Industrial $\mathrm{SO}_{2}$} \\
\hline & $(25)$ & (26) & (27) & (28) & $(29)$ & $(30)$ \\
\hline & pollution & $t f p$ & pollution & pollution & $t f p$ & pollution \\
\hline nor $\times$ time 1 & $\begin{array}{l}0.175^{* *} \\
(2.06)\end{array}$ & $\begin{array}{l}-0.014^{* * *} \\
(-2.29)\end{array}$ & $\begin{array}{l}0.178^{* *} \\
(2.29)\end{array}$ & $\begin{array}{l}0.169^{*} \\
(1.77)\end{array}$ & $\begin{array}{l}-0.014^{* * *} \\
(-2.29)\end{array}$ & $\begin{array}{l}0.177^{*} \\
(1.91)\end{array}$ \\
\hline$t f p$ & & & $\begin{array}{l}-0.478 \\
(-1.03)\end{array}$ & & & $\begin{array}{l}-0.222 \\
(-0.52)\end{array}$ \\
\hline Control & yes & yes & yes & yes & yes & yes \\
\hline$u_{i}$ & yes & yes & yes & yes & yes & yes \\
\hline$\delta_{t}$ & yes & yes & yes & yes & yes & yes \\
\hline Bootstrap & & & $2.49^{* *}$ & & & $1.90^{*}$ \\
\hline$R^{2}$ & 0.374 & 0.572 & 0.371 & 0.535 & 0.572 & 0.546 \\
\hline Obs & 480 & 450 & 450 & 480 & 450 & 450 \\
\hline
\end{tabular}

$*, * *, * * *$ respectively represent that the estimated values of parameters are significant at the levels of $10 \%, 5 \%$, and $1 \%$. The value of $T$ is in parentheses
Table 5 Influence mechanism test of the international financial crisis on the north-south gap of industrial pollution discharge (1) and the south, is the impact of the international financial crisis on the north-south gap of industry pollution discharge related to the industrial structure? At the same time, there are some differences in the economic extroversion between the north and the south. Is the impact of the international financial crisis on the north-south gap of industrial pollution discharge related to economic extroversion?

In order to solve the above problems, this paper chooses industry structure isu and economic extroversion ftd for heterogeneity analysis. As for the industry structure, Chenery (1986) divides the manufacturing industry into the representative industry in the early stage of industrialization (the first type of industry), the representative industry in the middle stage of industrialization (the second type of industry) and the representative industry in the late stage of industrialization (the third type of industry). Referring to the research results of Fan (2008), Li and Wang (2016), and the National Industries Classification (GB/T4754-2017), this article selects the general equipment manufacturing industry, the special equipment manufacturing industry, the obvious differences in industry structure between the north 
Table 6 Influence mechanism test of the international financial crisis on the north-south gap of industrial pollution discharge (2)

\begin{tabular}{|c|c|c|c|c|c|c|}
\hline \multirow[t]{3}{*}{ Variable } & \multicolumn{3}{|c|}{ Industrial wastewater } & \multicolumn{3}{|c|}{ Industrial $\mathrm{SO}_{2}$} \\
\hline & (31) & (32) & (33) & (34) & (35) & (36) \\
\hline & pollution & $c r$ & pollution & pollution & $\mathrm{cr}$ & pollution \\
\hline nor $\times$ time 1 & $\begin{array}{l}0.175^{* *} \\
(2.06)\end{array}$ & $\begin{array}{l}-0.145^{* *} \\
(-2.25)\end{array}$ & $\begin{array}{l}0.175^{* *} \\
(2.21)\end{array}$ & $\begin{array}{l}0.169^{*} \\
(1.77)\end{array}$ & $\begin{array}{l}-0.145^{* *} \\
(-2.25)\end{array}$ & $\begin{array}{l}0.174^{*} \\
(1.86)\end{array}$ \\
\hline$c r$ & & & $\begin{array}{l}-0.063 \\
(-1.27)\end{array}$ & & & $\begin{array}{l}-0.042 \\
(-0.72)\end{array}$ \\
\hline Control & yes & yes & yes & yes & yes & yes \\
\hline$u_{i}$ & yes & yes & yes & yes & yes & yes \\
\hline$\delta_{t}$ & yes & yes & yes & yes & yes & yes \\
\hline Bootstrap & & & $2.00 * *$ & & & $1.70^{*}$ \\
\hline$R^{2}$ & 0.374 & 0.592 & 0.371 & 0.535 & 0.572 & 0.546 \\
\hline Obs & 480 & 450 & 450 & 480 & 450 & 450 \\
\hline
\end{tabular}

$*, * *, * * *$ respectively represent that the estimated values of parameters are significant at the levels of $10 \%, 5 \%$, and $1 \%$. The value of $T$ is in parentheses automotive industry, the railway, shipbuilding, aerospace and other equipment manufacturing industries, the electrical machinery and equipment manufacturing industry, the computer, communications and other electronic equipment manufacturing industry, the instrument machinery manufacturing industry as the third type of industry, and use the proportion of the third type of industry output value in the total industrial output value to measure industry structure. The original data of industry structure comes from the China Industry Statistical Yearbook. As for economic extroversion, this paper uses the proportion of total imports and exports in GDP to measure, and the original data comes from the China Statistical Yearbook.

Table 7 Heterogeneity analysis results

\begin{tabular}{|c|c|c|c|c|}
\hline Variable & $\begin{array}{l}(37) \\
i w w\end{array}$ & $\begin{array}{l}(38) \\
i w g\end{array}$ & $\begin{array}{l}(39) \\
i w w\end{array}$ & $\begin{array}{l}\text { (40) } \\
i w g\end{array}$ \\
\hline nor $\times$ timel & $\begin{array}{l}0.325^{* * * *} \\
(3.19)\end{array}$ & $\begin{array}{l}0.415^{* * * *} \\
(3.11)\end{array}$ & $\begin{array}{l}0.273^{* * * *} \\
(2.83)\end{array}$ & $\begin{array}{l}0.302^{* * * *} \\
(2.83)\end{array}$ \\
\hline$i s u$ & $\begin{array}{l}-0.553 \\
(-0.95)\end{array}$ & $\begin{array}{l}-0.714 \\
(-1.18)\end{array}$ & & \\
\hline nor $\times$ time $1 \times i s u$ & $\begin{array}{l}-0.871^{* *} \\
(-2.60)\end{array}$ & $\begin{array}{l}-1.446^{* * * *} \\
(-2.90)\end{array}$ & & \\
\hline$f t d$ & & & $\begin{array}{l}-0.125 \\
(-0.55)\end{array}$ & $\begin{array}{l}-0.112 \\
(-0.90)\end{array}$ \\
\hline nor $\times$ time $1 \times f t d$ & & & $\begin{array}{l}-0.410^{* * * *} \\
(-3.34)\end{array}$ & $\begin{array}{l}-0.550^{* * * *} \\
(-4.68)\end{array}$ \\
\hline Control & yes & yes & yes & yes \\
\hline$u_{i}$ & yes & yes & yes & yes \\
\hline$\delta_{t}$ & yes & yes & yes & yes \\
\hline $\mathrm{R}^{2}$ & 0.391 & 0.586 & 0.406 & 0.576 \\
\hline Obs & 450 & 450 & 480 & 480 \\
\hline
\end{tabular}

$*, * *, * * *$ respectively represent that the estimated values of parameters are significant at the levels of $10 \%, 5 \%$, and $1 \%$. The value of $T$ is in parentheses
Table 7 shows the results of the heterogeneity analysis. It can be seen from Table 7 that the interaction coefficients of industry structure in column (37) and (38) are significantly negative, indicating that industry structure upgrading weakens the effect that "the international financial crisis relatively increases the industrial pollution discharge in the north." In Table 7, the interaction coefficients of economic extroversion in columns (39) and (40) are both significantly negative, indicating that economic extroversion weakens the effect that "the international financial crisis relatively increases the industrial pollution discharge in the north."

\section{Empirical analysis on the causes of the change in north-south gap in 2016}

\section{Benchmark regression results}

The regression results of the benchmark model are shown in Table 8. In Table 8, columns (41) and (42) are the regression results without adding other control variables. Columns (43) and (44) are the regression results with control variables but without individual and time fixed effects. Columns (45) and (46) are the regression results with control variables, individual and time fixed effects. Columns (47) and (48) are the regression results of the growth rate of industrial pollution discharge.

As can be seen from Table 8, no matter whether control variables and fixed effects are added, the interaction coefficients aren't significant ${ }^{3}$, indicating that the supplyside structural reform has no significant impact on the

\footnotetext{
3 The interaction coefficient in column (43) is significant, but it does not conform to the actual situation.
} 
Table 8 The impact of the supply-side structural reform on the north-south gap in industrial pollution discharge
Table 9 Influence mechanism test of the supply-side structural reform on the north-south gap of growth rate of industrial pollution discharge (1)

\begin{tabular}{lllllllll}
\hline Variable & $(41)$ & $(42)$ & $(43)$ & $(44)$ & $(45)$ & $(46)$ & $(47)$ & $\begin{array}{l}(48) \\
\end{array}$ \\
& $i w w$ & $i w g$ & $i w w$ & $i w g$ & $i w w$ & $i w g$ & giww & giwg \\
\hline nor & $-0.172^{* * *}$ & $0.520^{* * *}$ & $-0.509^{* * *}$ & $-0.150^{* *}$ & & & & \\
& $(-3.02)$ & $(8.02)$ & $(-10.76)$ & $(-2.38)$ & & & & \\
time2 & $-0.549^{* * *}$ & $-1.27^{* * *}$ & $-0.464^{* * *}$ & $-0.748^{* * *}$ & $-0.998^{*}$ & $-3.592^{* * *}$ & -0.306 & $-0.407^{* * *}$ \\
& $(-5.84)$ & $(-10.79)$ & $(-6.69)$ & $(-7.38)$ & $(-1.71)$ & $(-5.57)$ & $(-1.22)$ & $(-3.03)$ \\
nor $\times$ time 2 & 0.039 & -0.111 & $0.228^{* *}$ & 0.117 & 0.001 & -0.113 & $-0.073^{* *}$ & $-0.083^{* *}$ \\
& $(0.32)$ & $(-0.53)$ & $(2.49)$ & $(0.83)$ & $(0.01)$ & $(-0.75)$ & $(-2.32)$ & $(-2.57)$ \\
Control & no & no & yes & yes & yes & yes & yes & yes \\
$u_{i}$ & no & no & no & no & yes & yes & yes & yes \\
$\delta_{t}$ & no & no & no & no & yes & yes & yes & yes \\
$R^{2}$ & 0.170 & 0.438 & 0.522 & 0.773 & 0.599 & 0.898 & 0.241 & 0.675 \\
Obs & 420 & 420 & 420 & 420 & 420 & 420 & 420 & 420 \\
\hline
\end{tabular}

$*, * *, * *$ respectively represent that the estimated values of parameters are significant at the levels of $10 \%, 5 \%$, and $1 \%$. The value of $T$ is in parentheses

\begin{tabular}{|c|c|c|c|c|c|c|}
\hline \multirow[t]{3}{*}{ Variable } & \multicolumn{3}{|c|}{ Industrial wastewater } & \multicolumn{3}{|c|}{ Industrial $\mathrm{SO}_{2}$} \\
\hline & (49) & $(50)$ & $(51)$ & $(52)$ & (53) & $(54)$ \\
\hline & growth & $t f p$ & growth & growth & $t f p$ & growth \\
\hline nor $\times$ time 2 & $\begin{array}{l}-0.073^{* *} \\
(-2.32)\end{array}$ & $\begin{array}{l}0.028^{* *} \\
(2.52)\end{array}$ & $\begin{array}{l}-0.079^{* *} \\
(-2.48)\end{array}$ & $\begin{array}{l}-0.083^{\text {** }} \\
(-2.57)\end{array}$ & $\begin{array}{l}0.028^{* *} \\
(2.52)\end{array}$ & $\begin{array}{l}-0.088^{* *} \\
(-2.57)\end{array}$ \\
\hline$t f p$ & & & $\begin{array}{l}0.202 \\
(0.82)\end{array}$ & & & $\begin{array}{l}0.167 \\
(0.85)\end{array}$ \\
\hline Control & yes & yes & yes & yes & yes & yes \\
\hline$u_{i}$ & yes & yes & yes & yes & yes & yes \\
\hline$\delta_{t}$ & yes & yes & yes & yes & yes & yes \\
\hline Bootstrap & & & $1.96^{* *}$ & & & $2.32^{* *}$ \\
\hline$R^{2}$ & 0.241 & 0.431 & 0.242 & 0.675 & 0.431 & 0.675 \\
\hline Obs & 420 & 420 & 420 & 420 & 420 & 420 \\
\hline
\end{tabular}

$*, * * * * *$ respectively represent that the estimated values of parameters are significant at the levels of $10 \%, 5 \%$, and $1 \%$. The value of $T$ is in parentheses north-south gap of industrial wastewater discharge and industrial $\mathrm{SO}_{2}$ discharge. After replacing the industrial pollution discharge with the growth rate of industrial pollution discharge, the interaction coefficients are significantly negative, indicating that the supply-side structural reform makes the growth rate of industrial wastewater discharge and industrial $\mathrm{SO}_{2}$ discharge in the northern region decrease compared with the southern region, or the supply-side structural reform makes the growth rate of industrial wastewater discharge and industrial $\mathrm{SO}_{2}$ discharge in the southern region increase compared with the northern region. Although the regression results of industrial pollution discharge are inconsistent with the results of status analysis and theoretical analysis, the regression results of industrial pollution discharge growth rate are very significant, which proves the correctness of Hypothesis 2 to a certain extent.

\section{Influence mechanism test}

Table 9 and Table 10 show the test results of mediation variables. For $t f p$, it can be seen from Table 9 that the interaction coefficient in column (49) is significantly negative, indicating that the supply-side structural reform relatively reduces the growth rate of industrial wastewater discharge in the north. The interaction coefficient in column (50) is significantly positive, indicating that the supply-side structural reform relatively improves the total factor productivity in the north. Although the regression coefficient of tfp in column (51) is not significant, it passes the bootstrap test, indicating that the supply-side structural reform can relatively reduce the growth rate of industrial wastewater discharge in the north by improving the total factor productivity in the north, thus widening the north-south gap of growth rate of 
Table 10 Influence mechanism test of the supply-side structural reform on the north-south gap of growth rate of industrial pollution discharge (2)

\begin{tabular}{|c|c|c|c|c|c|c|}
\hline \multirow[t]{3}{*}{ Variable } & \multicolumn{3}{|c|}{ Industrial wastewater } & \multicolumn{3}{|c|}{ Industrial $\mathrm{SO}_{2}$} \\
\hline & $(55)$ & $(56)$ & $(57)$ & (58) & (59) & (60) \\
\hline & growth & $c r$ & growth & growth & $c r$ & growth \\
\hline nor $\times$ time 2 & $\begin{array}{l}-0.073^{* *} \\
(-2.32)\end{array}$ & $\begin{array}{l}0.449^{* *} \\
(2.65)\end{array}$ & $\begin{array}{l}-0.086^{* * *} \\
(-2.75)\end{array}$ & $\begin{array}{l}-0.083^{* *} \\
(-2.57)\end{array}$ & $\begin{array}{l}0.449^{* *} \\
(2.65)\end{array}$ & $\begin{array}{l}-0.088^{* *} \\
(-2.63)\end{array}$ \\
\hline$c r$ & & & $\begin{array}{l}0.028 \\
(1.48)\end{array}$ & & & $\begin{array}{l}0.012 \\
(0.86)\end{array}$ \\
\hline Control & yes & yes & yes & yes & yes & yes \\
\hline$u_{i}$ & yes & yes & yes & yes & yes & yes \\
\hline$\delta_{t}$ & yes & yes & yes & yes & yes & yes \\
\hline Bootstrap & & & $2.07 * *$ & & & $2.46^{* *}$ \\
\hline$R^{2}$ & 0.241 & 0.374 & 0.243 & 0.675 & 0.373 & 0.675 \\
\hline Obs & 420 & 420 & 420 & 420 & 420 & 420 \\
\hline
\end{tabular}

$*, * *, * * *$ respectively represent that the estimated values of parameters are significant at the levels of $10 \%, 5 \%$, and $1 \%$. The value of $T$ is in parentheses industrial wastewater discharge. Similarly, for $c r$, according to Table 10, the interaction coefficient in column (55) is significantly negative, indicating that the supply-side structural reform relatively reduces the growth rate of industrial wastewater discharge in the north. The interaction coefficient in column (56) is significantly positive, indicating that the supply-side structural reform relatively improves the economic endogenous growth rate in the north. Although the regression coefficient of $c r$ in column (57) is not significant, it passes the bootstrap test, indicating that the supply-side structural reform can relatively reduce the growth rate of industrial wastewater discharge in the north by improving the economic endogenous growth rate in the north, thus widening the north-south gap of growth rate of industrial wastewater discharge. The test results of industrial $\mathrm{SO}_{2}$ are consistent with those of industrial wastewater, which will not be repeated here.

\section{Robustness test}

In order to ensure the robustness of the regression results, this paper still makes up policy time to test the robustness. Table 11 shows the results of the placebo test with 2008-2015 as the policy time. This paper finds that the interaction coefficients are not significant when the policy time is 2008-2012, while the interaction coefficients are significantly negative when the policy time is 2013-2015, indicating that the regression results of this paper are not robust.

\section{Discussion}

In order to verify the correctness of the theoretical hypotheses, this paper uses DID to study the impact of the international financial crisis in 2008 and the supply-side structural reform in 2016 on the north-south gap of industrial pollution discharge in China. In the empirical analysis of the change of the north-south gap in 2008, firstly, the benchmark regression results show that the international financial crisis in 2008 significantly changed the north-south gap of industrial pollution discharge in China, which preliminarily proves the correctness of Hypothesis 1 . According to theoretical analysis, the difference in the impact of the international financial crisis on the industrial pollution discharge in northern and southern China is mainly due to the difference in the ways to deal with the international financial crisis and restore economic growth in northern and southern China. The northern region mainly relies on steel, petrochemical, and other capital-intensive industries to restore economic growth, while the southern region mainly relies on the development of knowledge-intensive industries and industrial transformation and upgrading to restore economic growth. The difference in economic growth pattern leads to the difference of TFP and TFP contribution rate, and then leads to the difference of industrial pollution discharge.

Secondly, in order to ensure the robustness of benchmark regression results, this paper uses four methods to test the robustness, such as common trend test, making up experimental groups and policy time, and changing sample time range. All the results of robustness tests show that the benchmark regression results and research conclusions in this paper are very robust. Then, through the mediation model, this paper finds that the two mediating variables both pass the mediating effect test, and the international financial crisis can affect the north-south gap of industrial pollution discharge through total factor productivity and economic endogenous growth rate, which further clarify the influence mechanism of the international financial crisis on the northsouth gap. Finally, in order to explore whether the impact of the international financial crisis on the north-south gap 
Table 11 Placebo test results based on fictitious policy time

\begin{tabular}{lllllllll}
\hline Variable & $(61)$ & $(62)$ & $(63)$ & $(64)$ & $(65)$ & $(66)$ & $(67)$ & $(68)$ \\
& 2008 & 2009 & 2010 & 2011 & 2012 & 2013 & 2014 & 2015 \\
\hline nor $\times$ time 2 & 0.022 & 0.010 & 0.010 & -0.032 & -0.019 & $-0.043^{*}$ & $-0.053^{* *}$ & $-0.056^{* *}$ \\
$($ giww $)$ & $(0.56)$ & $(0.25)$ & $(0.33)$ & $(-1.01)$ & $(-0.74)$ & $(-1.82)$ & $(-2.08)$ & $(-2.05)$ \\
nor $\times$ time 2 & -0.040 & -0.041 & -0.031 & -0.030 & $-0.065^{* * *}$ & $-0.086^{* * *}$ & $-0.092^{* * *}$ & $-0.089^{* * *}$ \\
(giwg) & $(-1.33)$ & $(-1.48)$ & $(-1.42)$ & $(-1.50)$ & $(-3.60)$ & $(-3.13)$ & $(-3.09)$ & $(-2.81)$ \\
Control & yes & yes & yes & yes & yes & yes & yes & yes \\
$u_{i}$ & yes & yes & yes & yes & yes & yes & yes & yes \\
$\delta_{t}$ & yes & yes & yes & yes & yes & yes & yes & yes \\
$R^{2}($ iww $)$ & 0.231 & 0.230 & 0.231 & 0.233 & 0.231 & 0.235 & 0.236 & 0.236 \\
$R^{2}(i w g)$ & 0.670 & 0.670 & 0.670 & 0.669 & 0.674 & 0.678 & 0.679 & 0.677 \\
Obs & 420 & 420 & 420 & 420 & 420 & 420 & 420 & 420 \\
\hline
\end{tabular}

$*, * *, * * *$ respectively represent that the estimated values of parameters are significant at the levels of $10 \%, 5 \%$, and $1 \%$. The value of $T$ is in parentheses of industrial pollution discharge is affected by other factors, this paper makes the heterogeneity analysis. The results show that industry structure upgrading and economic extroversion weaken the effect of "the international financial crisis relatively decreases the industrial pollution discharge in the south." For industry structure upgrading, this paper holds that under the impact of the international financial crisis, the northern region mainly relies on steel, petrochemical, and other capital-intensive industries to restore economic growth. Therefore, the more advanced the industry structure of a northern province, the less the proportion of capital-intensive industries, the weaker the effect of economic stimulus measures, and the smaller the increase of industrial pollution discharge. On the contrary, under the impact of the international financial crisis, the southern region mainly relies on the development of knowledge-intensive industries and industrial transformation and upgrading to restore economic growth. Therefore, the more advanced the industry structure of a southern province, the more the proportion of knowledge-intensive industries, the smaller the space for industrial transformation and upgrading, and the smaller the decrease of industrial pollution discharge. It can be seen that the weakening effect of the industrial structure upgrading is realized under the joint action of the north and the south. For economic extroversion, theoretically, a region with a higher economic extroversion is more affected by the international financial crisis, and has a greater impact on the north-south gap of industrial pollution discharge. However, the regression results in Table 7 are completely opposite to the theoretical analysis. This paper argues that such a result may be due to the hysteresis of the transmission of the international financial crisis. The international financial crisis has a greater impact on the regions with high economic extroversion in the initial stage. As time goes by, the impact of the international financial crisis will gradually be transmitted to the regions with low economic extroversion. In China, the economic extroversion roughly follows the distribution of "gradually decreasing from east to west." A region with a lower economic extroversion has a lower industrial structure and a weaker self-recovery ability. Therefore, a region with a lower economic extroversion may eventually be much more affected by the international financial crisis than a region with a high economic extroversion, and have a greater impact on the north-south gap of industrial pollution discharge.

In the empirical analysis of the change of the north-south gap in 2016, firstly, the benchmark regression results show that the supply-side structural reform in 2016 significantly changed the north-south gap of industrial pollution discharge's growth rate in China, which preliminarily proves the correctness of Hypothesis 2. According to theoretical analysis, the difference in the impact of the supply-side structural reform on the growth rate of industrial pollution discharge in northern and southern China is also due to the difference in the economic growth patterns in northern and southern China. Before the supply-side structural reform, the northern region still highly relied on steel, petrochemical, and other capital-intensive industries to maintain economic growth, while the southern region mainly relied on knowledge-intensive industries to promote economic growth after completing industrial transformation and upgrading with the help of the international financial crisis. Under the pressure of cutting overcapacity and reducing excess inventory, the industrial pollution discharge in the northern and southern regions both decreased significantly. However, the differences in economic growth pattern in the northern and southern regions lead to the differences in the amount of tasks of cutting overcapacity, and further lead to the differences in TFP and TFP contribution rates, as well as the differences in the growth rates of industrial pollution discharge. Then, the results of the mediation model show that the supplyside structural reform can also affect the north-south gap of 
industrial pollution discharge through total factor productivity and economic endogenous growth rate, which further clarify the influence mechanism of the supply-side structural reform on the north-south gap. Finally, in the robustness test, this paper finds that the coefficient of the interaction term is significant only after the policy time point is advanced to after 2013. Why did the north- south gap in the growth rate of industrial pollution discharge change from 2013? In order to answer this question, this paper reviews the relevant policy documents and finds that the central government first proposed "cutting overcapacity" not in 2016, but in 2013. In 2013 , the new central government came into office, attached great importance to environmental protection and overcapacity, and promulgated and implemented a series of related policies and regulations. Among them, the Notice of the State Council on Printing and Distributing the Air Pollution Prevention and Control Action Plan (GF [2013] No.37) proposed for the first time to reduce pollutant discharge by accelerating the elimination of backward production capacity and promoting industrial transformation and upgrading. Later, the Guidance of the State Council on Resolving the Contradiction of Serious Overcapacity (GF [2013] No.41) further emphasized the importance and urgency of resolving the contradiction of serious overcapacity, and defined the overall requirements, basic principles, and main objectives of resolving overcapacity. This paper argues the task of cutting overcapacity proposed by the supply-side structural reform in 2016 is essentially a further continuation of the policy of "resolving overcapacity" implemented by the central government in 2013. In fact, local governments have gradually resolved the contradiction of overcapacity and promoted industrial transformation and upgrading in accordance with the relevant policy documents of the central government since 2013. Therefore, the north-south gap in the growth rate of industrial discharge changed from 2013.

In previous studies, scholars pay more attention to the north-south gap of economy in China, and few scholars pay attention to the north-south gap of environmental pollution. When studying the reasons for the widening north-south gap of economy in China, scholars have given different explanations and formed a few mainstream views, including natural resources theory (Wu 2001), culture theory (Liu 2008), policy theory (Zhao and Wei 2015), factor theory (Bian et al. 2018), and structure theory (Yang and Huang 2020). This paper is the first to study the north-south gap in industrial pollution discharge, and deeply analyzes the reasons behind the change of the north-south gap of industrial pollution discharge. The research results are innovative and enrich literature on the regional gap of environmental pollution. At the same time, this paper studies from the perspective of economic growth pattern transformation, and the research results further expand the research conclusions of Deng et al. (2020). It indicates that the transformation of economic growth pattern will not only cause the widening of the north-south gap of economy but also cause the change of the north-south gap of industrial pollution discharge.

\section{Conclusions and policy implications}

\section{Research conclusions}

(1) In essence, the difference in economic growth pattern transformation in the northern and southern regions is the root cause of the change in the north-south gap of industrial pollution discharge.

(2) The international financial crisis is the direct cause of the change in the north-south gap of industrial pollution discharge in 2008. The international financial crisis forced the industrial transformation and upgrading of the southern region, which made the TFP and economic endogenous growth rate of the southern region relatively improve, and then led to the relative reduction of industrial pollution discharge in the southern region. At the same time, the heterogeneity analysis results show that industry structure upgrading and economic extroversion weaken the effect of "the international financial crisis relatively decreases the industrial pollution discharge in the south."

(3) The supply-side structural reform is the direct cause of the change in the north-south gap of industrial pollution discharge in 2016. The supply-side structural reform forced the industrial transformation and upgrading of the northern region, which made the TFP and economic endogenous growth rate of the northern region relatively improve, and then led to the relative decrease of growth rate of industrial pollution discharge in the northern region. However, the supply-side structural reform proposed by the central government in 2016 is essentially a further continuation of the policy of "resolving overcapacity" implemented in 2013. In fact, the north-south gap in the growth rate of industrial discharge has changed since 2013.

\section{Policy suggestions}

(1) Transforming the economic growth pattern and promoting industrial upgrading are the fundamental measures to ensure that the north-south gap of industrial pollution discharge remains in a reasonable range for a long time. In order to promote economic growth, the northern regions should not support backward industries with high pollution and high-energy consumption, but pay more attention to environmental pollution, actively transform the economic growth pattern, and adjust industrial structure. Specifically, we can start from the three aspects to transform the economic growth pattern and adjust industrial structure. Firstly, 
at the regional level, the local governments should scientifically formulate industrial layout planning, strengthen the adjustment of regional industrial layout, gradually optimize regional industrial layout. Secondly, at the industrial level, the local governments should promote the development of energy conservation and environmental protection industry, clean production industry, and clean energy industry. Finally, at the enterprise level, the local governments could stimulate the green development power of enterprises, reduce the cost of green transformation of enterprises, and support enterprises to enhance green manufacturing capacity.

(2) The central government must adhere to the strategy of innovation-driven development, and cannot repeat the mistake of massive economic stimulus plan after the international financial crisis in 2008. Since the international financial crisis, the southern region has vigorously promoted the development of the Internet, artificial intelligence, and intelligent manufacturing. Not only have the TFP and economic endogenous growth rate been greatly improved but also the industrial pollution discharge has been greatly reduced. But the north-south gap of industrial pollution discharge further widened because that the north region supports backward industries. The northern region later improved TFP to a certain extent and reduced industrial pollution discharge by resolving overcapacity. However, in order to maintain the endogenous growth power for a long time and achieve the coordinated development of economic growth and ecological environment, the northern region must adhere to the innovation driven development strategy. In the new economic tide represented by the digital economy, the northern region should actively learn from the advanced experience of the southern region, cultivate new momentum, and shape new advantages based on local advantages. At the same time, the northern region should strengthen exchanges and cooperation with the southern region, avoid strategic convergence and blind investment, and return to the old path of sacrificing the ecological environment for economic growth.

(3) Deepen the supply-side structural reform and further promote the work of "cutting overcapacity." The supplyside structural reform greatly reduced the industrial pollution discharge in both the north and the south, and kept the north-south gap relatively stable. In the critical period when the global COVID-19 epidemic is stabilizing and China's economy is gradually recovering, the central government must continue to push forward the work of "cutting overcapacity." Specifically, we can start from two aspects to resolve overcapacity. On the one hand, the central government should encourage local governments to formulate policies to eliminate backward production capacity with wider scope and higher standards by improving financial incentives and other measures, increase the intensity of eliminating backward production capacity. On the other hand, the local governments should strictly implement national investment management regulations and industrial policies, strengthen project management in the "high pollution and high energy consumption" industries, and strictly control the new production capacity in the "high pollution and high energy consumption" industries.

Author contribution BL put forward the research question and determined research ideas. AA found the research data. JL completed the status analysis section. XZ completed the theoretical and empirical analysis, and was a major contributor in writing the manuscript. All authors read and approved the final manuscript.

Funding The study is supported by the Natural Science Foundation of Hunan Province (2018JJ2067).

Data availability All data generated or analyzed during this study are included in this published article [and its supplementary information files].

\section{Declarations}

Competing interests The authors declare have no competing interests.

\section{References}

Bao Q, Shao M, Yang DL (2013) Environmental Regulation, Provincial Legislation and Pollution Emission in China. Econ Res J 48(12):42-54 (in Chinese)

Baron RM, Kenny DA (1986) The moderator-mediator variable distinction in social psychological research: conceptual, strategic, and statistical considerations. J Pers Soc Psychol 51(6):1173-1182

Bian YC, Wu LH, Bai JH (2018) High-speed rail, factor flow and regional economic disparities. Finance \& Trade Economics 39(06):147-161 (in Chinese)

Brajer V, Mead RW, Xiao F (2011) Searching for an Environmental Kuznets Curve in China's air pollution. China Econ Rev 22(3):383-397

Chen ZH, Leizhu JH (2015) The spatial-temporal characteristics and economic drivers of environmental pollution changes in China. Econ Geogr 34(11):2165-2178 (in Chinese)

Chenery HB (1986) Comparative study on industrialization and economic growth. Shanghai SDX Joint Publishing Company. (in Chinese), pp 57-78

Cheng Y, Xu CL, Ren JL, Liu L (2014) Atmospheric environment effect of industrial structure evolution in Shandong Province. China Popul Resour Environ 24(01):157-162 (in Chinese)

Deng ZQ, Gao TF, Zhu F (2020) China's regional gap and supply-side structural reform: endogenous growth in a transition period. Econ Res J 55(10):22-37 (in Chinese)

Ding HF, Li PY (2010) Analysis on Regional Pollution Feature of China. Econ Geogr 30(03):501-507 (in Chinese)

Dong F, Yu B, Pan Y, Hua Y (2020) What contributes to the regional inequality of haze pollution in China? Evidence from quantile regression and Shapley value decomposition. Environ Sci Pollut Res 27(14):17093-17108

Dutheil F, Baker JS, Navel V (2020) Covid-19 as a factor influencing air pollution? Environ Pollut 263(Pt A):114466 
Fan FZ (2008) Structure change and industry upgrading in China's industry:1985-2005. Stat Res 25(07):19-25 (in Chinese)

Friedl B, Getzner M (2003) Determinants of $\mathrm{CO}_{2}$ emissions in a small open economy. Ecol Econ 45(1):133-148 (in Chinese)

He W, Liu CY, Liu J, Guo SL (2015) Environmental regulation, technology change, and air pollution: a panel study on Tianjin. Sci Sci Manag S T 36(05):51-56 ((in Chinese))

Hu A G, Cheng W Y and Yan Y L. (2018). Transformation of principal contradiction in Chinese society and supply-side structural reform. Journal of Nanjing University (Philosophy, Humanities and Social Sciences), 55(01), pp. 5-16+157. (in Chinese)

Huang JR, Shen J, Cai LM, Zhang WK (2021) The effects of emission trading scheme on industrial output and air pollution emissions under city heterogeneity in China. J Clean Prod 315:128260

Huang HJ, Lv CJ, Edward L (n.d.) The influence of "Four Trillion Investment" policy on firm investment efficiency. Accounting Research, (02), pp. 51-57+96. (in Chinese)

Li J, Wang PP (2016) The effect of population urbanization on upgrading of industrial structure. Ind Econ Res 04:29-38 (in Chinese)

Li JK, Cheng LY, Zhang TB (2017) Does foreign direct investment have the pollution halo effect? China Population, Resources and Environment 27(10):74-83 (in Chinese)

Lin BQ, Jiang ZJ (2009) Prediction of environmental Kuznets curve of carbon dioxide in China and analysis of its influencing factors. Management World 187(04):27-36 (in Chinese)

Liu H (2008) Thirty years of chinese economy viewed by 50 people: review and analysis. Beijing: Economic Press China. (in Chinese)

Liu FY, Zhao AQ (2016) Test for the effect of foreign direct investment on environmental pollution in cities: empirical analysis of panel data from 285 cities. J Int Trade 401(05):130-141 (in Chinese)

Liu MZ, Yang JX, Ma D, Ding ZH (2015) Spatial disparity and factor analysis of major air pollutant emissions in China based on LMDI method. Resources Science 37(02):333-341 (in Chinese)

Liu YW, Wen XQ, Hu ZY (2016) Analysis on the difference and convergence in pollutant emission in China. The Journal of Quantitative \& Technical Economics 33(04):78-94 (in Chinese)

Luo YM, Teng Y (2018) Regional difference in soil pollution and strategy of soil zonal governance and remediation in China. Bull Chin Acad Sci 33(02): 145-152 (in Chinese)

Qi HQ, Wang ZT (2015) Research on the change of emission differences and its income partition countermeasures in China. The Journal of Quantitative \& Technical Economics, 32(12), pp. 57-72+141. (in Chinese)

Russo MA, Relvas H, Gama C, Lopes M, Monteiro A (2019) Estimating emissions from tourism activities. Atmos Environ 220:117048

Sheng LY, Zheng X, Zhou P, Li T (2018) Analysis on the causes of the widening economic north-south gap in China. Management World 34(09): 16-24 (in Chinese)

Shi MJ, Zheng D, Lei P, Yuan JP (2017) Evolution of spatial pattern of industrial wastewater pollution emission in China. China Population, Resources and Environment 27(05):1-7 (in Chinese)

Shi DQ, Ding H, Wei P, Liu JJ (2018) Can smart city construction reduce environmental pollution. China Industrial Economics 363(06):117-135 (in Chinese)

Singpai B, Wu DS (2020) An integrative approach for evaluating the environmental economic efficiency. Energy 215:118940

Wang P, Xie LW (2014) Pollution control investment, enterprise technical innovation and pollution control efficiency. China Population, Resources and Environment 24(09):51-58 (in Chinese)
Wang PG, Xu CL (2015) Research on the comprehensive evaluation of China's environmental health, 2003-2010. Soc Indic Res 122(3):709-721

Wang F, Dong SC, Mao QL (2014) Evolution of China's industrial structure and spatial-temporal differentiation in environmental effect. Geogr Res 33(10):1793-1806 (in Chinese)

Weiwei Z, Yaqin Z, Yu Y (2020) China's regional environmental efficiency evaluation: a dynamic analysis with biennial Malmquist productivity index based on common weights. Environ Sci Pollut Res Int 27(32):39726-39741

Wen ZL, Zhang L, Hou JT, Liu HY (2004) Testing and application of the mediating effects. Acta Psychol Sin 36(5):614-620 (in Chinese)

Wu DY (2001) A study on north-south differences in economic growth. Geogr Res 02:238-246 (in Chinese)

Xiao T, Liu H (2014) Empirical study on industrial structure adjustment and energy conservation and emission reduction. Economist 09:58-68 (in Chinese)

Xinchen M, Xingle L (2016) Static and dynamic analysis on the environmental efficiency of 267 cities in China during 2004-2012. Asian Agric Res, (10), pp. 44-45+50.

Yang MH, Huang P (2020) Study on the measurement of structural effect and spatial difference in the gap between the north and the south of China. Inquiry into Economic Issues, (05), pp. 1-13. (in Chinese)

Yang Q, Liu HJ (2012) Regional difference decomposition and influence factors of China's carbon dioxide emissions. The Journal of Quantitative \& Technical Economics, 29(05), pp. 36-49+148. (in Chinese)

Yu CL, Gao HJ (2015) The effect of environmental regulation on environmental pollution in China based on the hidden economy perspective. China Industrial Economics, (07), pp. 21-35. (in Chinese)

Yuan YJ, Xie RK (2012) Industrial structure adjustment, technological progress and pollution abatement. China Population, Resources and Environment 22(S2):144-147 (in Chinese)

Yuan Y, Xi QM, Sun TS, Li GP (2016) The impact of the industrial structure on regional carbon emission: empirical evidence across countries. Geogr Res 35(01):82-94 (in Chinese)

Zhang H, Wei XP (2014) Green paradox or forced emission-reduction: dual effect of environmental regulation on carbon emissions. China Population, Resources and Environment 24(09):21-29 (in Chinese)

Zhang Y, Wu FP (2015) Study on the effect of decomposition factors of industrial wastewater discharge in China based on LMDI method. Ind Econ Res 79(06):99-110 (in Chinese)

Zhang C, Lu Y, Guo L, Yu TS (2011) The intensity of environmental regulation and technological progress of production. Econ Res $\mathbf{J}$ 46(02):113-124 (in Chinese)

Zhao Y, Wei HK (2015) The government intervention, the division of labor of the function of the space of the city group, and the difference in district: on the effectiveness of regional policy in China. Management World, (08), pp. 14-29+187. (in Chinese)

Zhou K, Fan J (2016) Regional disparity of environmental pollution source and its socio-economic influencing factors: based on the cross-section data of 339 cities at prefecture level or above in China. Acta Geograph Sin 71(11):1911-1925 (in Chinese)

Publisher's note Springer Nature remains neutral with regard to jurisdictional claims in published maps and institutional affiliations. 